\title{
Intellectual Growth For Undergraduate Students: Evaluation Results From An Undergraduate Research Conference
}

Sharyn J. Potter, University of New Hampshire, USA Eleanor Abrams, University of New Hampshire, USA

Lisa Townson, University of New Hampshire, USA

Cameron Wake, University of New Hampshire, USA

Julie E. Williams, University of New Hampshire, USA

\begin{abstract}
We describe the development and evaluation of the university-wide, weeklong undergraduate research conference at the University of New Hampshire. Despite increases nationally in the number of undergraduate research conferences $(U R C)$, there has been little research examining the social and educational impact of these events on student presenters. We describe the development and evaluation of the university-wide, weeklong URC at the University of New Hampshire. A survey administered to URC participants over a four year period revealed that research culminating in a presentation at the URC was one of the more influential events students experienced during their undergraduate years and students realized a high level of satisfaction from presenting at the URC.
\end{abstract}

Keywords: Undergraduate research conference, student experience, evaluation

\section{INTRODUCTION}

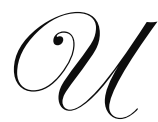

ndergraduate research infuses the curricula at many research universities. It is a critical element in helping undergraduates understand their chosen discipline (Jenkins, Breen, Lindsay \& Brew, 2003). Encouraged by several commissions, such as the Boyer Commission, with its seminal 1998 report, research universities are increasing opportunities for undergraduate students to be immersed in real-world investigations (Hu, Kuh, \& Gayles, 2007). While research is defined differently, depending upon the discipline, a research project usually involves a question, exploration of that question through methodologies inherent to the discipline, the drawing of conclusions, and communicating the findings to others.

Several studies (Bandura, Wre, Davis, \& Smith, 2000; Hunter, Larsen, \& Seymour, 2006; Lopatto, 2003; Seymour, Hunter, Larsen, \& Deantoni, 2004; Voight, 1996) note multiple benefits for undergraduates immersed in the research process; i.e. enhanced critical thinking, encouragement of collaborative learning, refined communication skills, improved organizational skills, and well-developed feelings of competence. Students report other benefits from presenting their work at an Undergraduate Research Conference (URC), such as the opportunity to present their work in front of peers and faculty and the ability to discuss a topic of interest with others (Merkel, 2003).

Another benefit that can come from undergraduate research experiences includes that of enhanced faculty/student interactions. Through interactions with faculty members and colleagues with similar interests, students who conduct and present research discover at least part of what it would be like to be a professional in their chosen field (Collins, 2001). The undergraduate research experience often facilitates the development of mentoring relationships between faculty and student. Previous research on faculty mentoring explains that, in a mentoring relationship, an experienced professional trains the newcomer about profession or discipline specific practices, 
expectations and norms (Ekrut \& Mokros, 1984; Folse, 1991; Waldeck, Orrego, Plax, \& Kearney, 1997). Facultystudent interaction not only results in motivating students to pursue a job or graduate school, but also provides them with the personal contacts often required to open doors to other opportunities beyond graduation. In fact, Collins (2001) notes that employers and graduate schools value research, presentation, and publication experience. In a study of clinical psychology programs, graduate admission directors found that research experience or a commitment to research was the most important factor in determining admittance (Munoz-Dunbar \& Stanton, 1999).

While the benefits of undergraduate research experiences have been studied, a focus on the perceptions of undergraduates involved in such activities has not been well researched. Previous studies have focused on senior honor thesis work, senior capstone experiences or research conducted by seniors in highly-intensive mentoring relationships with faculty (Hunter et al, 2006; Seymour et al, 2004). Often, the project results are presented at the annual conferences of the discipline.

This research explores the perceptions of undergraduate students involved in research across a variety of settings, including class projects, senior capstone experiences, senior and honor theses and independent study experiences. The students surveyed presented their work at an annual on-campus University of New Hampshire Undergraduate Research Conference (URC) (Abrams, 2009). We wondered if students considered participation in the URC a valuable experience and how URC participation compares with other academic experiences.

\section{Overview of URCs}

URCs or celebrations of student research highlight student research, scholarship, and sometimes creativity by offering students venues (usually on campus) to present their work. URCs vary widely in the number of students involved as well as the quality of the events (Crowe \& Sienerth, 2006). Many colleges and departments offer small URCs each year for their students, which may or may not be well attended (Crowe \& Sienerth, 2006). Occasionally, universities offer a larger university-wide event as a way to unify the campus (Crowe \& Sienerth, 2006). While there is some literature on organizing and administering a URC (Squire \& Hyre, 2004), there is no published research that describes university-wide student assessments of the value of their research experience including the presentation at a URC.

\section{Undergraduate Research Conference at the University of New Hampshire}

UNH is a public university set in a fairly rural area about 70 miles north of Boston. UNH is a land-, sea-, and space-grant institution with 11,845 undergraduate students, 2,359 graduate students, and 976 faculty members. UNH received $\$ 99$ million in research funding during the 2008-09 academic year.

\section{URC Within the University Structure}

Typical of many higher education institutions, the types of undergraduate research presentations vary widely - from loosely structured departmental events to more formally-structured events that give students a chance to present their scholarship in front of peers, colleagues, and faculty. Ten years ago, the UNH URC added a small University-wide event to its offerings. Three years after that, with a small influx of resources and leadership from the Office of the Vice President for Research, the UNH URC expanded further, and has since grown into a weeklong celebration of student inquiry and creativity, featuring more than 20 events on two campuses with approximately 900 student participants.

Students from a wide range of disciplines conduct undergraduate research and share their work in various URC venues. Depending on their discipline, UNH URC participants have opportunities to give research talks, discuss and exhibit posters, present mechanical inventions, and present their fine art, theater, or music projects.

\section{University Wide Commitment to the UNH URC}

Faculty and staff from across campus dedicate themselves to offering professional venues for student presentations. Planners strive to have the URC emulate a professional conference. Changes aimed at reaching this 
goal include the development of a dedicated URC Web site (http://www.unh.edu/urc) that provides detailed information about events, two URC promotional video and information on how to create an effective oral presentation or poster. An online registration system was created that gives students the option to send a personalized electronic invitation ("e-vite") to friends and family encouraging them to attend their presentation. A professionally-designed conference program ${ }^{1}$ is published and distributed each year. Finally the committee worked with university marketing experts and students from a marketing class to develop a widespread recruitment campaign aimed at potential undergraduate presenters and faculty mentors; and creating a community-wide promotional campaign to attract conference guests.

\section{Recruitment}

Recruitment of student presenters begins in the fall semester using a variety of materials to attract attention to the event, including dining hall table tents, student newspaper advertisements, posters, articles in on-campus media outlets, presentations by students in large general education classes, and electronic ads on the UNH homepage. In addition, encouraging faculty to engage undergraduates in research occurs through a variety of means, including orientation for new faculty, connecting with departmental undergraduate research representatives, departmental meeting presentations, and e-mail reminders of registration opening and closing dates. Once registration is closed, communications shift to focus on raising audience attendance, using on-campus, local, regional, and statewide media and a range of advertising and marketing

\section{EVALUATION STRATEGY}

The tenth-annual UNH URC took place in 2009. Eight hundred seventy-two students participated - the highest number in the event's history - at more presentation venues and with more faculty participation than ever before. Despite the success and growth, up to that point no formal effort to assess the overall experience and postgraduation impact on student participants had been initiated. Efforts to evaluate the impact of undergraduate research began in 2006, and have continued every year through 2009. Each year current participants are surveyed during the week following the conclusion of URC.

\section{RESEARCH QUESTIONS}

The purpose of this research was to examine if and how the URC experience impacts the quality of a student's perceived academic experience. The following questions formed the focus of our research:

1. How do current students perceive the URC impacting their undergraduate experience?

2. How do current students perceive their mentors' role in their academic/research experience?

\section{METHODS}

The following section describes the methods used to investigate current URC participants. The University Internal Review Board approval was obtained before the research began. In keeping with the theme of the URC, undergraduate students participated in all aspects of the URC evaluation, including instrument design, data collection and analysis, and result presentations. The quantitative data was analyzed using SPSS version 15 . The qualitative data from the open ended questions on the student surveys and the faculty interview data were analyzed by three faculty researchers and two student researchers. The research team looked for themes and discrepancies in the qualitative data and discussed in detail each discrepancy that arose to ensure that there was unanimous agreement regarding the interpretation and resulting classification of the qualitative data.

\section{Survey administration}

One week after the 2006, 2007, 2008 and 2009 conferences, using e-mail addresses obtained in the URC online registration, the survey committee e-mailed all URC student presenters. The e-mail asked these students for voluntary participation, and included a direct survey link. Comprising the survey were 13 closed-ended and two open-ended questions. Survey questions focused on: participant demographics; satisfaction with the URC 
registration process and event, and perceptions about skills gained as a result of participating in the URC. Finally, students were asked to evaluate and describe their URC faculty mentoring experience. Those who participated in the survey would have a chance to win an iPod Nano. The average survey response rate for each of the 4 years of the study was $40 \%$.

\section{RESULTS}

\section{Demographic Data}

On average, $61 \%$ of female and $39 \%$ of male URC participants responded to the on-line survey. In the fours years of our study approximately $37 \%$ of the URC survey participants were enrolled in the College of Life Sciences and Agriculture and the College of Engineering and Physical Sciences. Students in the College of Liberal Arts made up $39 \%$ of the survey participants. Seventy-five percent of respondents were in their senior year at UNH and $86 \%$ indicated that this was the first time they had participated in the URC. Eleven percent of the students surveyed were presenting at URC for their second time, while only $2 \%$ were presenting for their third time (Table $1)$.

Thirty-five percent of the student respondents indicated that they presented senior thesis work at the URC. Approximately $33 \%$ of survey respondents indicated they presented class project work. Other respondents indicated the work described in their presentations stemmed from a faculty mentor's ongoing research, suggesting that faculty members include undergraduate students in their research agendas. Thirty-eight percent of students indicated that they received research funding from a variety of sources, including faculty grants and University undergraduate research grants (Table 1).

Table 1: Demographic Characteristics of Student Participants Responding to Survey

\begin{tabular}{|c|c|c|c|c|c|}
\hline 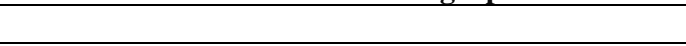 & All years & 2006 & 2007 & 2008 & 2009 \\
\hline URC participants sent survey & 2653 & 333 & 632 & 816 & 872 \\
\hline \multirow[t]{2}{*}{ URC participants responding to survey (sample size) } & 1060 & 135 & 209 & 330 & 386 \\
\hline & \multicolumn{5}{|c|}{ Percent of total $(\%)$} \\
\hline \multicolumn{6}{|l|}{ Gender } \\
\hline Male & 39 & 36 & 37 & 40 & 44 \\
\hline Female & 61 & 63 & 64 & 60 & 56 \\
\hline \multicolumn{6}{|l|}{ Year } \\
\hline Senior & 75 & 73 & 78 & 77 & 71 \\
\hline Junior & 17 & 23 & 13 & 13 & 18 \\
\hline Sophomore & 6 & 2 & 8 & 6 & 8 \\
\hline Freshman & 2 & 1 & 0 & 4 & 3 \\
\hline \multicolumn{6}{|l|}{ Number of time student presented } \\
\hline First year & 86 & 88 & 87 & 87 & 89 \\
\hline Second year & 11 & 11 & 11 & 11 & 10 \\
\hline Third year & 2 & 1 & 2 & 2 & 1 \\
\hline \multicolumn{6}{|l|}{ College } \\
\hline Life Sciences \& Agriculture & 17 & 20 & 15 & 15 & 19 \\
\hline Engineering \& Physical Sciences & 20 & 21 & 24 & 20 & 13 \\
\hline Liberal Arts & 39 & 41 & 43 & 35 & 35 \\
\hline Health \& Human Services & 6 & 8 & 6 & 6 & 4 \\
\hline Business School & 16 & 9 & 7 & 23 & 24 \\
\hline Other & 2 & 1 & 5 & 1 & 5 \\
\hline \multicolumn{6}{|l|}{ Project Origin } \\
\hline Senior Thesis & 35 & 30 & 44 & 32 & 35 \\
\hline Class Project & 33 & 30 & 28 & 37 & 35 \\
\hline Faculty Mentor's Ongoing Research & 21 & 25 & 20 & 19 & 21 \\
\hline Other & 11 & 15 & 8 & 12 & 9 \\
\hline Percent of students receiving funding & 38 & 44 & 19 & 46 & 42 \\
\hline
\end{tabular}




\section{Impact of the URC Experience}

This section of the survey was designed to assess how participation in the URC affected students' communication, research, and presentation skills. Using a five-point Likert scale ranging from 1=URC had no influence, to 5=URC was very influential, those surveyed answered questions on presentation creation, public speaking, sharing ideas with colleagues, and confidence in taking initiative. Eighty-six percent of survey participants reported that the URC experience was very influential in developing their ability to create presentations. Eighty-five percent of survey participants indicated that the URC experience was very influential in giving them the confidence to take initiative (Table 2).

Table 2: Reported Impact of URC Experience by Participants

\begin{tabular}{|c|c|c|}
\hline & Influential & No Impact \\
\hline \multicolumn{3}{|c|}{ Experience Impact on Presentation Creation (\%) } \\
\hline All years & 86 & 14 \\
\hline 2009 & 87 & 13 \\
\hline 2008 & 87 & 13 \\
\hline 2007 & 81 & 19 \\
\hline 2006 & 87 & 13 \\
\hline \multicolumn{3}{|c|}{ Public Speaking (\%) } \\
\hline All years & 84 & 16 \\
\hline 2009 & 92 & 8 \\
\hline 2008 & 82 & 18 \\
\hline 2007 & 78 & 22 \\
\hline 2006 & 83 & 17 \\
\hline \multicolumn{3}{|c|}{ Sharing Ideas with Colleagues (\%) } \\
\hline All years & 95 & 15 \\
\hline 2009 & 86 & 14 \\
\hline 2008 & 90 & 10 \\
\hline 2007 & 83 & 17 \\
\hline 2006 & 84 & 16 \\
\hline \multicolumn{3}{|c|}{ Confidence in Taking Initiative (\%) } \\
\hline All years & 85 & 15 \\
\hline 2009 & 85 & 15 \\
\hline 2008 & 86 & 14 \\
\hline 2007 & 84 & 16 \\
\hline 2006 & 87 & 13 \\
\hline
\end{tabular}

In addition, respondents were asked to rate their URC experience compared with other experiences at the UNH. Using a Likert-type scale, students ranked their experience from "not memorable" to "the most memorable experience." Thirty-eight percent of respondents ranked the URC experience as either their most or one of their most memorable experiences at UNH. Fifty-six percent ranked their URC experience as average and only $7 \%$ ranked their experience as not memorable or lower than average (Table 3 ).

Table 3: Overall Impact of URC Experience Reported by Survey Participants

\begin{tabular}{lccc}
\hline $\begin{array}{l}\text { Impact of Experience in Relationship to } \\
\text { Undergraduate to Undergraduate Career }\end{array}$ & Most Memorable & Average & Not Memorable \\
\hline All years (\%) & & & 7 \\
$2009(\%)$ & 38 & 56 & 6 \\
$2008(\%)$ & 36 & 58 & 8 \\
$2007(\%)$ & 38 & 54 & 8 \\
$2006(\%)$ & 35 & 57 & 5 \\
\hline
\end{tabular}


Survey participants in all four years of the study $(2006,2007,2008$ and 2009) described their interactions with faculty mentors in an overwhelmingly positive manner. In data not shown, $82 \%$ of all the survey respondents indicated "yes," when asked if faculty mentoring throughout the URC experience positively influenced their educational outcomes. More than half of respondents provided additional comments. Six percent of respondents shared negative opinions and only $7 \%$ shared neutral opinions regarding their faculty mentors' influence. Students who expressed dissatisfaction with their faculty mentor cited lack of support and little communication as primary reasons. In a few cases, students did not feel their faculty mentor had enough experience or understanding of the URC and were unable to help them prepare adequately. A few others felt their faculty mentor did not make an effort to be engaged in their work, and were disappointed their mentor did not attend their presentation.

Responses to open-ended question described students' most memorable URC experiences and provided additional feedback on their faculty mentors. Although short answer data appears to be similar to qualitative data, the responses to these questions do not fit easily into typical qualitative analyses associated with non-numerical data. A hybrid method was used where responses were read as a whole initially, with the researcher taking notes in the margins of text, in order to gain an overall sense of the data. An iterative, winnowing process was used to find themes in the data that exist and tentative themes were identified and data coded for each theme (Creswell, 1998).

Respondents identified increased confidence and pride in $22 \%$ of their open-ended responses; improved communication and presentation skills in $35 \%$ of their open-ended responses; and an enhanced understanding of the research process through firsthand experience conducting research that impacts the larger community in 20\% responses, as some of the benefits of presenting their research at URC.

\section{Confidence, Pride, Communication and Presentation Skills}

Student survey participants recognized the value of the URC as a means to improve their presentation skills and confidence when speaking to others about their work. They praised their faculty mentors for helping them through the research process and providing them with confidence. Several survey participants mentioned the pride they experienced in completing their research and making a formal presentation. According to one survey participant;

Practice in presenting ideas visually as well as verbally was tremendous. Technical skills learned on how to create pleasing yet educational posters are two skills that I may not have necessarily learned through a class. Also, on the spot questioning and trying to come up with a valid answer helped my social skills.

Another student indicated that "the most memorable part was finishing my presentation and feeling as though I had accomplished something very challenging. It made me proud and gave me more academic confidence." Respondents explained that their faculty mentors helped them learn about research in new ways and gave them the confidence they would need for the future. URC survey participants felt well supported by their mentors, and explained that their mentors positively influenced their UNH experiences. Respondents also indicated that their faculty mentors were influential when they were making decisions about post-graduation plans, including graduate school and/or careers. About this, one respondent commented,

My faculty mentor has been the most influential person in my undergraduate career. He has provided me with more experience, knowledge, and opportunity than any class could offer. I am completely indebted for his support and confidence in me.

Further, in their written comments, 24 of more than 600 student survey participants report that faculty mentors play an important role in providing connections and opportunities for students to enter graduate programs or the job market. Respondents mentioned the importance of having their family members at the conference to see their work. The importance of sharing accomplishments with parents was a strong theme throughout responses. According to one participant, "...having my parents in the audience was an honor and allowed me to show them all the hard work I have been doing throughout the semester." 


\section{Increased knowledge about the research process}

Students from both years reported that they had a much greater knowledge and appreciation for the research process. They appreciated the opportunity to explore questions of their own and learn from mistakes. One student said; "My mentor has allowed me to get involved and see what the "real world" of biology is all about." Another student said; "My mentor did a good job of letting us get experience learning how to lead a project, deal with conflict, problem solve, etc. He let us make mistakes, even costly ones. This was very beneficial." Yet another student indicated; "The development process and production of a research project takes time, initiative, tons of motivation, knowledge, and thrill for the subject matter."

\section{Impact on Larger Community}

All URC events include some form of question and answer session. Respondents from the 2007 URC, in particular, expressed an appreciation for this dialogue with others. They enjoyed answering questions, meeting other students and faculty members with similar academic interests, and seeing what other students had accomplished. They appreciated the questions and comments from faculty and community members attending. One student indicated,

One of the most rewarding aspects of presenting my research during the URC was the opportunity to discuss the project with students and faculty from other academic areas. These individuals brought different points of view based on their own work and experiences, which allowed them to ask questions of and make observations about my research that I had not considered. Being focused on one's particular field is certainly a good thing, but seeing how the work relates to the world as a whole is incredibly important. Sharing my research at the URC and talking with those who attended allowed me to expand certain ideas of my project, giving it greater depth and helping to determine its importance in the bigger picture.

\section{DISCUSSION AND CONCLUSION}

The UNH URC brings the research experience full circle by providing a professional venue for students to present their work and engage in thoughtful discussions with other members of the University community. The experience gives students the opportunity to learn and practice important communication skills required for success in their subsequent professional lives. This result does align with the results seen from studies of undergraduate research (Hunter et al., 2006; Seymour et al., 2004).

Responses from the current survey participants indicate that their participation in undergraduate research has a significant and positive effect on their educational and post-graduate experience. The URC experience increased student respondents' confidence and presentation skills and, in many cases, influenced their graduate school and/or career choices. URC survey participants also report a sense of pride in being able to plan, implement, and report their research to peers, faculty, and family members. For many, it was one of the more memorable experiences of their undergraduate career. Prior research corroborates the impact that undergraduate on communication and presentation skills (Kardash, 2000).

The student responses also highlight the critical role faculty mentors play in the URC experience, as the students indicated the relationships they developed with their faculty mentors made the research process fulfilling. Although there is little research on the benefits of faculty mentors and undergraduate students, the literature on faculty mentors and graduate students indicate that this can be a powerful and positive relationship. For instance, graduate students who have faculty mentors are more confident about their roles as professionals, are more satisfied with their graduate programs (Keith \& Moore, 1995), and are more successful in graduate school (Desmond \& Symens, 1997) than graduate students without mentors. Furthermore, graduate students with faculty mentors are more productive, have better publication records, and ultimately are more viable job-market candidates than those without mentors (Desmond \& Symens, 1997; Ekrut \& Mokros, 1984; Keith \& Moore, 1995).

While the mentoring experience is often a mutually-beneficial experience for faculty and their students, these results suggest faculty efforts should be rewarded. The students overwhelmingly attribute the success of their 
research and the resulting URC presentation to faculty mentoring. Although some researchers find that mentoring can have positive affects on their faculty careers (Wright \& Wright, 1987), mentoring undergraduate students remains a conundrum for faculty, as it is not valued by some academic departments and some University administrators. In many research universities, the pressures for faculty to publish do not provide appropriate incentives for mentoring undergraduate research. (Folse, 1991). The number of publications and external funding awards are more critical components of faculty promotion and tenure decisions than the number of students mentored or the number of hours faculty spend mentoring undergraduate research (Folse, 1991).

There is a need to recognize what Jenkins, Healey, and Zetter (2007) call the teaching-research nexus. The pursuit of knowledge in a community includes old timers of the discipline working with newcomers to teach them the knowledge, skills, values, and beliefs of the culture (Lave \& Wenger, 1991). Systematically recognizing the time and effort faculty spend mentoring URC participants in the form of awards, release time, or professional development, money would likely increase quality research opportunities for undergraduate students and thereby improve overall educational experiences.

URCs can positively impact the undergraduate experience and influence students' choices of graduate education and professions in all the disciplines. More work is needed to determine the level of support students need during their research, scholarship, and creative work to be able to present the results of that work at URCs. Further research is needed to determine what types of recognition could help energize faculty who are not currently mentors, so they, too, could play that critical role of mentor and guide to student researchers (e.g. Thomas \& Gillespie, 2008). Ongoing research about undergraduate research will provide institutions of higher education the ability to foster and promote the academic success of undergraduate students.

\section{Transferability to Other Higher Education Institutions}

The UNH URC is transferable to other institutes of higher education. Like many public and private universities, UNH is closely watching their expenditures and in some cases reducing expenditures. Yet at the same time research achievements of faculty and students are growing and faculty have come to realize that undergraduates can play an important part in the research process. The URC that we have successfully implemented at UNH over the past seven years does not require a large financial investment. Rather the success of the URC is dependent on university leaders' commitment to organizing and administering a professional research conference. The commitments of the UNH leadership members have set the tone for both faculty and staff and have made URC an integral component of the university culture. Members of the faculty and staff commit a great deal of their time to ensure the success of the event. The UNH URC is dependent on the staff from editorial and creative services, and printing services volunteering their time to this endeavor. Recent research demonstrates how undergraduate research experiences can be coupled with junior faculty development resulting in fulfilling experience for undergraduate students while providing mentoring and publication opportunities for junior faculty (Thomas \& Gillespie, 2008).

\section{Research Limitations}

We recognize that the quality and type of undergraduate research experienced by the students varied widely. This variation was not accounted for in the analysis of the data. The data in our analysis specifically included students who chose to present or were required to present their research at the UNH URC. We recognize that other students are involved in undergraduate research and may not choose to participate in the conference. From the survey results it is unclear if the URC presentation represents an endpoint in the student's research on their topic or if they are planning to continue with their research during the next academic year or during their graduate work. In future surveys we plan to include questions that enable us answer these questions. Additionally, we are in the process of developing a research plan to survey alumni to determine if their URC experience influenced their employment opportunities and decisions they made regarding graduate studies. Further, we plan to examine how members of the university faculty view their role as mentors, the time they commit to mentoring and what factors lead to their roles as mentors and the benefits they receive from serving as a mentor. 


\section{AUTHOR INFORMATION}

Dr. Sharyn J. Potter is an associate professor in the Department of Sociology at UNH. She has served on the UNH Undergraduate Research Conference (URC) Planning Committee for the past 7 years. For the past four years she has chaired the URC evaluation committee. She has studied how policy change impacts organizations, providers and clients. For the past six years Dr. Potter has helped lead the development and evaluation efforts of the Know Your Power Bringing in the Bystander Social Marketing Campaign. She is part of a research team that has received funding from the NIJ, DOJ and CDC.

Dr. Eleanor Abrams is an associate professor in the Department of Education at the University of New Hampshire. Dr. Abrams has edited one book and numerous articles investigating models of inquiry-based education in public education, effective instructional methods to teach science to undergraduate students and the effects of engaged scholarship on faculty development.

Dr. Lisa Townson currently serves as the Assistant Director for programs for University of New Hampshire Cooperative Extension. She has been a specialist in program development and evaluation for UNH Cooperative Extension for six years and has been involved on the UNH Undergraduate Research Conferences Evaluation subcommittee for four years. Lisa has been involved in numerous web-based survey research projects and additional areas of research interest include higher education, specifically university engagement and outreach scholarship.

Dr. Cameron P. Wake is the senior faculty fellow to the Associate Vice President for Research and Outreach Scholarship, and an Associate Research Professor in the department of Earth Sciences. He has served as the faculty director of the UNH Undergraduate Research Conference and works with the Associate Vice President to advance a number of the Office's engaged scholarship and research initiatives. Dr. Wake focuses his research on studies of regional climate and environmental change through the analysis of ice cores and instrumental records. Currently he is leading research programs to reconstruct climate change from ice cores recovered from glaciers on the Tibetan Plateau and in the Canadian Arctic. He is also involved in the AIRMAP project, which seeks to improve understanding of New England's changing climate and air quality. He leads the related INHALE project that is investigating the links between air quality and human health in New England. As part of the Northeast Climate Impact Assessment, he was co-lead on two research papers and a series of reports detailing past and future climate change in the US Northeast.

Dr. Julie E. Williams is senior vice provost for engagement and academic outreach at the University of New Hampshire. Her primary responsibilities are leading the institution's public engagement mission, building collaborative interdisciplinary and multi-institutional research and education partnerships, and creating faculty professional development opportunities for engaged scholarship. The UNH undergraduate research conference (URC) reports to her office and over the last eight years her team has lead the transformation of the URC. She also leads efforts to enhance the university's presence at key federal agencies including the National Science Foundation and the National Endowment for the Humanities. She received her doctorate in clinical psychology from the University of Tennessee-Knoxville and was an American Council on Education fellow.

\section{REFERENCES}

1. Abrams, E. (2009). The Undergraduate Research Conference - A Key Ingredient in the sustainable learning community. In Kelly, T, J Aber, \& B. Mallory, The sustainable learning community: One University's journey to the future. (pp.185-188). Hanover, NH: University Press of New England.

2. $\quad$ Bandura, A.S., Wre, M.E., Davis, S.F., \& Smith, R.A. (2000). Teaching beyond the classroom: Mentoring student publications and presentations. Paper presented at the Annual Conference of the American Psychological Association (108 ${ }^{\text {th }}$, Washington, D.C., August 4-8, 2000).

3. Collins, L.H. (2001). Does research experience make a significant difference in graduate admissions? PSI CHI, 5(2), 1-4.

4. Creswell, J. W. (1998). Qualitative inquiry and research design: Choosing among five traditions. Thousand Oaks, CA: Sage Publications. 
5. Crowe, M., \& Sienerth, K. (2006). Budgeting for a centralized office of undergraduate research. Council on Undergraduate Research, 27, 54-60.

6. Desmond, S. A., \& Symens, A. M. (1997). Promoting graduate students' membership in professional organizations. Teaching Sociology, 25, 176-182.

7. Ekrut, S., \& Mokros, J. R. (1984). Professors as models and mentors for college students. Educational Research Journal, 21, 339-417.

8. Folse, K. A. (1991). Ethics and the profession: Graduate student training. Teaching Sociology, 19, 344-350.

9. Hu, S., Kuh, G.D., \& Gayles, J.G. (2007). Engaging Undergraduate students in research activities: Are research universities doing a better job? Innovative Higher Education, 32,167-177.

10. Hunter, A., Laursen, S.L., \& Seymour, E. (2006). Becoming a scientist: the role of undergraduate research in students' cognitive, personal, and professional development. Science Education, 91, 36-74.

11. Jenkins, A., Breen, R., Lindsay, R., \& Brew, A. (2003). Re-shaping higher education: Linking teaching and research. London: Routledge/Falmer.

12. Jenkins, A., Healey, M., \& Zetter, R. (2007). Linking teaching and research in departments and disciplines. York: The Higher Education Academy http://www.heacademy.ac.uk/ourwork/research/teaching.

13. Kardash, C.M. (2000). Evaluation of an undergraduate research experience: Perceptions of undergraduate interns and their faculty mentors. Journal of Educational Psychology, 92,191-201.

14. Keith, B., \& Moore, H. A. (1995). Training sociologists: An assessment of professional socialization and the emergence of career aspirations. Teaching Sociology, 23, 199-214.

15. Lopatto, D. (2003). The essential features of undergraduate research. Council on Undergraduate Research Quarterly, March, 139-142.

16. Lave, J., \& Wenger, E. (1991). Situated learning: Legitimate peripheral participation. Cambridge, MA: Cambridge University Press.

17. Merkel, C. A. (2003). Undergraduate research at the research universities. New Directions for Teaching and Learning, 93, 39-53.

18. Munoz-Dunbar, R., \& Stanton, A.L. (1999). Ethnic diversity in clinical psychology: Recruitment and admission practices among doctoral programs. Teaching of Psychology, 26, 259-263.

19. Seymour, E., Hunter, A., Laursen, S. L., \& Deantoni, T. (2004). Establishing the benefits of research experiences for undergraduates in the sciences: First findings from a three year study. Science Education, 88(4), 493-534.

20. Squire, J.C., \& Hyre, M.R. (2004). Running an Undergraduate Research Conference - Session 1725. Proceedings of the 2004 American Society for Engineering Education Annual Conference \& Exposition. American Society for Engineering Education.

21. Thomas, E., \& Gillespie, D. (2008). Weaving together undergraduate research, mentoring of junior faculty, and assessment: The Case of an Interdisciplinary Program. Innovative Higher Education, 33, 29-38.

22. Voight, P.A. (1996). Optimizing student research: Forming partnerships with undergraduate honors research programs. Paper presented at the Annual Meeting of the Speech Communication Association $\left(82^{\text {nd }}\right.$, San Diego, CA, November 23-26, 1996).

23. Waldeck, J. H., Orrego, V. O., Plax, T. G., \& Kearney, P. (1997). Graduate student/faculty mentoring relationships: Who gets mentored, how it happens and to what end. Communication Quarterly, 45, 93-109.

24. Wright, C. A., \& Wright, S. D. (1987). The role of mentors in the career development of young professionals. Family Relations, 36, 204-209.

\footnotetext{
${ }^{1}$ Access the program here: http://www.unh.edu/urc/pdf/09program.pdf
} 